\title{
Cholesterolaemic influence of palmitic acid in the $s n-1,3 v$. the $s n-2$ position with high or low dietary linoleic acid in healthy young men
}

\author{
C. E. Forsythe, M. A. French, Y. K. Goh and M. T. Clandinin* \\ Alberta Institute for Human Nutrition, Department of Agricultural, Food and Nutritional Science and Department of Medicine, \\ University of Alberta, 4-10 Agriculture/Forestry Centre, University of Alberta, Edmonton, Canada T6G 2P5
}

(Received 11 August 2006 - Revised 31 January 2007 - Accepted 2 February 2007)

\begin{abstract}
Healthy young men were fed four diets for 2 weeks each providing natural fats containing palmitic acid (16:0) predominantly in the $s n-1,3$ position of dietary TAG or containing $16: 0$ predominantly in the $s n-2$ position with low or high levels of linoleic acid (18:2n-6). Two treatments supplied 16:0 in the $s n-1,3$ positions from palmstearin with low ( $3 \%$ energy) or high ( $>7 \%$ energy) $18: 2 n-6$ and two treatments supplied $16: 0$ in the $s n-2$ position from lard with high or low levels of $18: 2 n-6$. Diets contained 30-35\% energy as fat, $7-11 \%$ energy as $16: 0$ and moderate levels of cholesterol. Fasting serum cholesterol and lipoprotein concentrations were measured. Cholesterol fractional synthesis rate (FSR) was determined by ${ }^{2} \mathrm{H}$ incorporation. Diets providing 16:0 in the $s n-2$ position resulted in lower fasting serum total cholesterol (TC) and a lower TC:HDL ratio than diets providing 16:0 in the $s n-1,3$ positions. Diets with high levels of $18: 2 n-6$ significantly decreased the TC:HDL ratio, reaffirming the well-known cholesterol-reducing effect of 18:2n-6. A lower non-esterified cholesterol FSR was observed with low dietary levels of $18: 2 n-6$. No differences between dietary treatments were found for serum HDL-cholesterol, LDL-cholesterol or TAG. It is concluded that dietary fats containing 16:0 in the $s n-2$ position may result in slightly lower fasting TC than diets providing 16:0 in the $s n-1,3$ positions, while the level of $n-6$ polyunsaturated fat influences endogenous cholesterol synthesis.
\end{abstract}

Cholesterolaemia: Palmitic acid: Lipid metabolism

Limitation of consumption of dietary fats rich in the SFA palmitic acid (16:0) to reduce risk factors for CVD has been debated based on investigations suggesting that 16:0 is not as hypercholesterolaemic as once implicated. Both animal (Khosla \& Hayes, 1993; Idris \& Sundram, 2002; Gupta et al. 2003) and human (Ng et al. 1992; Nestel et al. 1998; Clandinin et al. 2000; French et al. 2002) research has demonstrated that 16:0 may be considered neutral or 'conditionally' hypercholesterolaemic. This neutrality is contingent on the dietary content of linoleic acid $(18: 2 n-6)$ and cholesterol (Ng et al. 1992; Choudhury et al. 1997; Nestel et al. 1998; Clandinin et al. 2000; French et al. 2002). When $18: 2 n-6$ intake is greater than $5 \%$ total energy and cholesterol is less than $400 \mathrm{mg} / \mathrm{d}, 16: 0$ does not increase serum total or LDLcholesterol in healthy human subjects (Hayes \& Khosla, 1992; Sundram et al. 1995; Hayes, 1997; Clandinin et al. 2000; French et al. 2002).

Positional distribution of 16:0 in dietary TAG may also be a factor determining cholesterolaemic properties (Zock et al. 1995). During normal intestinal digestion, fatty acids are hydrolysed from the $s n-1,3$ positions of glycerol resulting in production of NEFA and 2-monoacylglycerols. Nonesterified SFA derived from the $s n-1,3$ positions may be absorbed less efficiently and have lesser influence on plasma cholesterol concentrations, given that these fatty acids have the potential to form insoluble soaps with $\mathrm{Ca}$ and $\mathrm{Mg}$, and be excreted in the faeces (Decker, 1996; Lien et al. 1997). In support of this, studies in infants (Filer et al. 1969; Innis et al. 1994) and adults (Yli-Jokipii et al. 2002; Emken et al. 2004) indicate that 75-80\% fatty acids in the $s n-2$ position of TAG are retained, and are incorporated into chylomicrons for transport in the circulation. Further, 16:0 in the $s n-2$ position of dietary TAG has been shown to be more atherosclerotic than 16:0 in the $s n-1,3$ positions when fed to rabbits (Kritchevsky, 1988; Kritchevsky et al. 2002). In human infants (Nelson \& Innis, 1999), feeding 16:0 in the $s n-2$ position increases fasting serum cholesterol concentrations compared with feeding 16:0 predominantly in the $s n-1,3$ positions. These observations imply that $16: 0$ found in the $s n-2$ position of dietary TAG may impart more hypercholesterolaemia than $16: 0$ in the $s n-1,3$ positions.

Investigations of normocholesterolaemic and hypercholesterolaemic adult human subjects have failed to show that feeding interesterified oils (those with randomised fatty acids) containing more $16: 0$ in the $s n-2$ position, compared with oils containing less $16: 0$ in the $s n-2$ position, result in a significant increase in serum total or LDL-cholesterol

\footnotetext{
Abbreviations: FSR, fractional synthesis rate; TC, total cholesterol.

* Corresponding author: Dr M. T. Clandinin, fax 1-780-492-8855, email tom.clandinin@ualberta.ca
} 
(Meijer \& Westrate, 1997; Nestel et al. 1998). Thus, altering the natural TAG structure of dietary fats through interesterification to provide less 16:0 in the $s n-2$ position may not affect fasting serum cholesterol concentrations in adults. However, few studies have compared feeding unaltered biological sources of dietary fat to adult human subjects containing fatty acids in different positional distributions on serum cholesterol and lipoprotein cholesterol levels. Palm oil and lard are two natural dietary fats containing high levels of 16:0 with differing positional distributions. Palm oil contains 16:0 esterified predominantly in the $s n-1$ and sn-3 position of glycerol (Kritchevsky et al. 2002) while lard contains 16:0 primarily in the $s n-2$ position (Myher \& Kuksis, 1979). Research has investigated the dietary influences of palm oil in human subjects and shown several conditions under which it is not hypercholesterolaemic (Ghafoorunissa, 1995; Khosla \& Sundram, 1997; Truswell, 2000); these results may be due to predominant esterification of $16: 0$ in the $s n-1,3$ position.

Based on these observations, the purpose of the present study is to compare the cholesterolaemic response of feeding $16: 0$ in the $s n-1,3$ positions from palmstearin with feeding $16: 0$ in the $s n-2$ position from lard in young normocholesterolaemic male subjects. The study also investigates the influence of dietary $18: 2 n-6$ content on source of $16: 0$, given the known cholesterol-reducing effects of $18: 2 n-6$ (Hayes \& Khosla, 1992; Hayes, 1997). The hypothesis is that feeding $16: 0$ in the $s n-1,3$ positions from palmstearin will be less cholesterolaemic than feeding $16: 0$ in the $s n-2$ position from lard, and 18:2n-6 content will modulate the cholesterolaemic response to both sources of $16: 0$. To determine cholesterolaemic effects, fasting serum cholesterol levels and $24 \mathrm{~h}$ cholesterol fractional synthesis rate (FSR), assessed by the ${ }^{2} \mathrm{H}$ incorporation method, are measured.

\section{Experimental methods}

\section{Subjects}

Procedures were approved by the Faculty of Agriculture, Forestry and Home Economics Human Ethics Review Committee (University of Alberta, Edmonton, Canada). All subjects gave written consent before the investigation. Ten male subjects with no history of medical problems and no family history of heart disease or hyperlipidaemia were recruited through advertisements posted at the University of Alberta. Eight subjects completed all aspects of the study. Each subject was interviewed to inform them of the study purpose, to explain expected responsibility and time commitment, and to outline dietary treatments. A questionnaire was completed by each participant to characterise activity level, food intake and sleeping patterns, and to provide information about food allergies and food dislikes. Subjects were willing to consume lard and pork products for a proportion of the study, and they agreed to only consume food given to them during the study while also refraining from alcohol and caffeine. Subjects were not taking any medications or supplements that would influence blood lipids or cardiovascular function. Fasting blood samples were obtained from each subject upon entry into the study to establish baseline values of serum cholesterol and TAG concentrations and confirm that they were all normocholesterolaemic.

\section{Subject energy requirements}

Energy requirements for each subject were determined using habitual $3 \mathrm{~d}$ food records and the Mayo Clinic Nomogram, incorporating the subjects' height, weight, age, sex and activity factor (Bell et al. 1985). Subjects were weighed daily before breakfast during the dietary feeding treatments to ensure body weight remained stable. Adjustments were made to energy intake if sustained weight changes were observed or if daily energy expenditure was altered.

\section{Dietary design}

The study design provided four dietary treatments of $14 \mathrm{~d}$ each with a 2 -week washout period between each treatment. Treatments over 2 weeks were selected based on previous investigations showing that steady-state plasma lipoproteins were achieved after 2-week diet treatments (Mattson \& Grundy, 1985). Each treatment consisted of a $3 \mathrm{~d}$ rotational menu portioned into three isoenergetic meals with a total of approximately $30 \%$ energy from fat, $15 \%$ energy from protein and $55 \%$ energy from carbohydrate. Diets were based on normal foods and designed using the Food Processor II nutrient analysis computer software program (ESHA Research, Salem, OR, USA). Each dietary treatment was balanced for $n-3$ fatty acids $(0 \cdot 25 \pm 0.1 \%$ total energy), cholesterol (range $250-360 \mathrm{mg} / \mathrm{d}$ ) and fibre content (19$26 \mathrm{~g} / \mathrm{d}$ ). Fatty acids were calculated from nutrient composition tables and laboratory analysis to provide high levels of 16:0 (about $8 \%$ total energy) with low and high levels of $18: 2 n-6$ ( 3 and $7-9 \%$ total energy respectively). Lard and pork products such as ham, bacon, sausage and pork chops were fed to provide a dietary source of 16:0 in the $s n-2$ position of TAG. Positional distribution of $16: 0$ in lard was determined from prior investigations (Renaud et al. 1995; Hunter, 2001) and contained approximately $65 \% 16: 0$ in the $s n-2$ position and $8 \%$ in the $s n-1,3$ positions. Palmstearin and a small amount of low-fat dairy products were fed to provide $16: 0$ in the $s n-1,3$ positions. Palmstearin contained approximately $23 \% 16: 0$ in the $s n-2$ position and $58 \%$ in the $s n-1,3$ positions. A high-linoleate safflower-seed oil was fed to provide a dietary source of $18: 2 n-6$. Depending on the dietary treatment, lard, palmstearin and safflower-seed oil were incorporated into common food items such as hash browns at breakfast, pitas and sandwiches at lunch, and pre-prepared entrées at dinner. Pre-prepared entrées obtained from Bassilis Best (Fabko Foods, Ltd, Edmonton, AB, Canada) were used for most lunch and dinner meals. These entrées contained low amounts of total fat $(4 \cdot 7-9.1 \mathrm{~g})$ and cholesterol $(31-35 \mathrm{mg})$ and were analysed before use to confirm fat content and fatty acid composition.

The four dietary treatments were fed in the following order: $s n-2$ 16:0 low-18:2n-6; sn-2 16:0 high-18:2n-6; $s n-1,3$ 16:0 low-18:2n-6; sn-1, 3 16:0 high-18:2n-6. Each subject consumed the same dietary treatment during the same period. Most dietary fat in the $s n-2$ 16:0 low$18: 2 n-6$ diet was provided by lard and pork products. 
In the $s n-1,316: 0$ low-18:2n-6 diet, the majority of fat was provided by palmstearin and monounsaturated fat from olive oil, mixed nuts and non-hydrogenated peanut butter. In all diets, the remaining fat sources were from egg yolks, beef, chicken, bagels, low-fat dinner buns, English muffins, waffles and pre-prepared entrées. Additional fruits and/or vegetables devoid of fat were permitted if needed. Clear herbal tea, decaffeinated coffee and sugarfree fruit juices were allowed.

Meals for each dietary treatment were prepared daily in the Human Nutrition Research Unit kitchen for consumption in the dining room (breakfast and lunch) or packaged for takeout (supper). Meals were consumed at regular intervals: 07.30-09.00 hours for breakfast, 11.30-13.00 hours for lunch and 17.30-19.00 hours for supper, depending on the individual participants' schedule. To assess compliance, dishware and containers were inspected upon return to ensure that all visible fat was eaten.

\section{Fat analysis of diets}

Diets were analysed for total fat and fatty acid composition. Duplicate samples for each meal in the $3 \mathrm{~d}$ menu of each dietary treatment were prepared. Meals were homogenised in a Sybron/Brinkman polytron (model PT 10/35; Sybron/Brinkman, Rexdale, ON, Canada) with the addition of water to a smooth paste. A sample of the blended food paste containing approximately $0.3-0.5 \mathrm{~g}$ fat was weighed and extracted with chloroform-methanol (2:1, v/v) (Folch et al. 1957). A known amount of tripentadecanoate (Sigma Chemical T4257; Sigma Chemical, St Louis, MO, USA) was added.

Fatty acid methyl esters were prepared with $\mathrm{BF}_{3}$ in methanol and quantified by automated GLC (Vista 3400 CX GLC and Vista 8200 data system; Varian Instruments, Georgetown, ON, Canada). Fatty acid methyl ester separation and identification was performed on a capillary column (DB20 $25 \mathrm{~m} \times 0.22 \mathrm{~mm}$ internal diameter; SGE Inc., Austin, TX, USA). Retention times of each of the fatty acid methyl esters were compared with those of a standard fatty acid methyl ester (Nu-Check Prep, Inc., Elysian, MN, USA) containing thirty-two known fatty acid methyl esters.

\section{Blood analysis}

On day 13 of each dietary treatment, a $30 \mathrm{ml}$ fasting blood sample was obtained by venepuncture between 07.30 and 09.00 hours. On day 12 , subjects were instructed to perform comparable amounts of physical activity and refrain from eating after 20.00 hours. Plasma was obtained by centrifugation $\left(3000 \mathrm{rpm}\right.$ for $10 \mathrm{~min}$ ) and frozen at $-20^{\circ} \mathrm{C}$. Day 13 plasma samples were outsourced for same-day analysis of total cholesterol (TC), LDL-cholesterol, HDL-cholesterol, TAG and C-reactive protein (Quest Diagnostics, Edmonton, $\mathrm{AB}, \mathrm{Canada})$. The plasma obtained on day 13 was used to determine baseline ${ }^{2} \mathrm{H}$ concentration in plasma water and plasma cholesterol, and the enriched plasma sample obtained on day 14 was used to determine ${ }^{2} \mathrm{H}$ enrichment over the $24 \mathrm{~h}$ period.
${ }^{2} \mathrm{H}$ incorporation for measurement of endogenous cholesterol biosynthesis

${ }^{2} \mathrm{H}$ incorporation is a stable isotope tracer methodology that measures cholesterolgenesis based on the rate of incorporation of ${ }^{2} \mathrm{H}$-labelled water into de novo synthesised non-esterified cholesterol. ${ }^{2} \mathrm{H}$-labelled water is a non-radioactive tracer that can be safely ingested and the enrichment of the precursor pool of cholesterol easily measured (Jones, 1990; Jones et al. 1993). The fundamental outcome measurement is the FSR of cholesterol, which is defined as the fraction of the rapidly turning over non-esterified cholesterol pool that is newly synthesised from a precursor pool (i.e. plasma water) over a $24 \mathrm{~h}$ period (Jones, 1990; Jones et al. 1993).

After the blood draw on day 13, subjects consumed a priming dose of ${ }^{2} \mathrm{H}$-labelled water at $0.5 \mathrm{~g}{ }^{2} \mathrm{H}$-labelled water $/ \mathrm{kg}$ estimated body water before breakfast was eaten. A maintenance dose of $1.0 \mathrm{~g}{ }^{2} \mathrm{H}$-labelled water $/ \mathrm{kg}$ estimated body water was then provided in a 2 litre bottle of water for consumption over the next $24 \mathrm{~h}$ to maintain plasma ${ }^{2} \mathrm{H}$ enrichment at plateau and to compensate for unlabelled water obtained in the diet. Body water was estimated as $60 \%$ total body mass (Altman, 1961; Jones et al. 1994a). On day 14, $24 \mathrm{~h}$ after the priming ${ }^{2} \mathrm{H}$-labelled water dose, a second fasting blood sample was collected.

\section{Determination of ${ }^{2} \mathrm{H}$ enrichment}

${ }^{2} \mathrm{H}$ enrichment was measured in plasma non-esterified cholesterol and plasma water as described previously (Kuksis \& Myher, 1989, Kuksis et al. 1990). To obtain non-esterified cholesterol, a $0.2 \mathrm{ml}$ sample of plasma and $1 \mathrm{ml}$ diethyl ether were added to a solution of 2 units phospholipase $\mathrm{C}$ in $2 \mathrm{ml}$ 17.5 mM-tri(hydroxymethyl)-aminomethane buffer ( $\mathrm{pH} 7 \cdot 3$ ) and $8 \mathrm{mg} 1 \% \mathrm{CaCl}_{2}$ (Kuksis et al. 1993). Samples were analysed in triplicate. The analyses were performed using an Agilent Model 6890 Thermo Finnigan DeltaPlus XL GC-pyrolysis-isotope ratio mass spectrometer (Thermo Finnigan MAT GmbH, Bremen, Germany) with an HP-5 capillary column $(30 \mathrm{~mm} \times 0.32 \mathrm{~mm}$ internal diameter and $0.25 \mu \mathrm{m}$ film thickness). The injector temperature was $325^{\circ} \mathrm{C}$ to ensure that the entire sample was volatilised. The split ratio was $10: 1$. The sample was injected on-column at $150^{\circ} \mathrm{C}$, held for $1 \mathrm{~min}$ and then the oven temperature was increased by $30^{\circ} \mathrm{C} /$ min to $200^{\circ} \mathrm{C}$, then $20^{\circ} \mathrm{C} / \mathrm{min}$ to $325^{\circ} \mathrm{C}$ and held for $5 \mathrm{~min}$. The analytical precision of the instrument was calculated from multiple analyses ( $n$ 96) of the hydrogen produced from the pyrolysis of the internal standard, tridecanoylglycerol. The coefficient of variability of the instrument was $4 \%$.

The ${ }^{2} \mathrm{H}$ enrichment in plasma body water was measured by the use of a Finnigan MAT 251 isotope ratio mass spectrometer (Thermo Finnigan MAT $\mathrm{GmbH}$ ) against hydrogen prepared from a water standard as described previously (French et al. 2002). Samples of day 14 plasma (enriched plasma), intended for measurement of plasma water enrichment, were diluted 20 -fold with $5 \%$ bovine serum albumin solution to lower the ${ }^{2} \mathrm{H}$ enrichment to within the analytical range of the isotope ratio mass spectrometer. Baseline day 13 samples were not diluted. The mass three abundance was corrected for $\mathrm{H}_{3}^{+}$contribution and determined daily. Multiple analyses of hydrogen produced from the reduction 
of laboratory water standard demonstrated the analytical precision $(\mathrm{CV})$ of this instrument at $<1 \%$. All samples were analysed in duplicate.

\section{Determination of cholesterol fractional synthesis rate}

Cholesterol FSR was determined from the initial incorporation rate of ${ }^{2} \mathrm{H}$-labelled cholesterol into the rapid exchangeable cholesterol pool relative to the initial precursor enrichment determined using body water ${ }^{2} \mathrm{H}$ level (Jones, 1990). Maximum attainable enrichment was calculated as body water pool enrichment corrected for the fraction of protons in de novo synthesised cholesterol that derive from water, relative to non-water sources (Jones, 1990; Jones et al. 1993) using the equation:

$$
\mathrm{FSR}_{\mathrm{NEC}}=\frac{\delta_{\mathrm{NEC}}}{\left(\delta_{\mathrm{PW}} \times 0,478\right)}
$$

where $\delta_{\mathrm{NEC}}$ is the change in enrichment in the total non-esterified cholesterol fraction and $\delta_{\mathrm{PW}}$ is the change in enrichment in the plasma water over $24 \mathrm{~h}$.

\section{Statistical methods}

A two-way ANOVA with repeated measures was used to determine the significance of dietary treatments on plasma lipids, Creactive protein and cholesterol FSR (SAS version 8.2; SAS Institute Inc., Cary, NC, USA). Significant differences were determined among dietary treatments by a Duncan's multiplerange test. Statistical significance was set at $P<0 \cdot 05$.

\section{Results}

\section{Subjects}

Ten subjects were enrolled in the study. One subject withdrew from the study because he developed digestive problems from eating more fat than he was accustomed. Another subject discontinued participation due to other time commitments that restricted him from consuming meals at the Human Nutrition Research Center each day. Eight subjects successfully completed each dietary treatment and compliance to the protocol was high (Table 1). All subjects maintained their baseline weight on the energy level assigned to them at the beginning of the study. Thus, body-weight fluctuations over the individual $14 \mathrm{~d}$ feeding treatments were negligible.

Table 1. Descriptive data of subjects $(n 8)$ completing the protocol

\begin{tabular}{|c|c|c|c|c|}
\hline & Age (years) & Mean weight (kg) & Height (cm) & BMI $\left(\mathrm{kg} / \mathrm{m}^{2}\right)$ \\
\hline & 28 & $89 \cdot 3$ & 170 & 28.0 \\
\hline & 26 & $75 \cdot 3$ & 175 & 24.5 \\
\hline & 27 & $64 \cdot 1$ & 173 & $21 \cdot 7$ \\
\hline & 28 & $86 \cdot 3$ & 180 & $26 \cdot 5$ \\
\hline & 26 & 108 & 187 & $28 \cdot 3$ \\
\hline & 24 & 88.5 & 195 & 24.5 \\
\hline & 21 & $73 \cdot 8$ & 190 & $20 \cdot 8$ \\
\hline & 27 & $69 \cdot 3$ & 182 & $20 \cdot 8$ \\
\hline Mean & 25.9 & $81 \cdot 8$ & 182 & 24.4 \\
\hline SD & $2 \cdot 4$ & $14 \cdot 1$ & $8 \cdot 7$ & $3 \cdot 1$ \\
\hline
\end{tabular}

\section{Habitual energy intakes of subjects}

Habitual dietary intake was 12639 (SD 2570) kJ. Mean percentage energy derived from saturated fat, protein and carbohydrate was 9 (SD 2), 17 (SD 4) and 49 (SD 8) \%, respectively. Mean habitual daily intake of cholesterol was 338 (sD 169) mg.

\section{Fatty acid analysis of lard and palmstearin}

Laboratory analysis of the fatty acid compositions of lard and palmstearin indicated that lard contained $40 \%$ total SFA, $27 \%$ $16: 0,15 \%$ stearic acid (18:0), $43 \%$ MUFA, 8.4\% 18:2n-6 and $95 \mathrm{mg}$ cholesterol $/ 100 \mathrm{~g}$. Palmstearin contained $70 \%$ total SFA, 63\% 16:0, 4.9\% 18:0, $24 \%$ MUFA, 5.3\% 18:2n-6 and no cholesterol/100 g.

\section{Dietary treatments and nutrient compositions}

Formulated nutrient content of diets and laboratory analysis of diets are shown (Table 2). The contribution of total energy from fat in each diet was $30-36 \%$. The difference in total fat and fatty acids between the laboratory analysis of diets and diets formulated by Food Processor was negligible except for the $s n-216: 0$ high-18:2n-6 diet. The $s n-216: 0$ high-18: $2 n-6$ diet provided $5 \%$ more energy from monounsaturated fat than formulated. Cholesterol intake was maintained within the range formulated. Diets that provided $s n-1,3$ 16:0 from palmstearin contained moderately less cholesterol than diets that provided $s n-2$ 16:0 from pork fat because palmstearin did not contain any cholesterol. There were no differences between dietary treatment with regards to intake of $n-3$ fatty acids (0.24 (SD 0.11) \% total energy), Ca (1052 (SD 62) $\mathrm{mg}$ ) or type and amount of dietary fibre (23.2 (SD 8.3) g). The polyunsaturated:saturated fat ratio was approximately $0 \cdot 32$ in the low-18:2n-6 diets and $0 \cdot 82$ in the high- $18: 2 n-6$ diets. Energy contribution of total $16: 0$ in the $s n-2$ position was based on data from Sheppard et al. (1978), with dairy lipid containing $43 \% 16: 0$ in the $s n-2$ position, lard containing $65 \% 16: 0$ in the $s n-2$ position, and palm oil containing $23 \% 16: 0$ in the $s n-2$ position. Table 2 shows the total contribution of energy as 16:0 from dairy lipid, lard and palmstearin.

\section{Plasma lipid and lipoprotein cholesterol levels}

Mean plasma lipid and lipoprotein cholesterol in subjects fed each dietary treatment are shown in Table 3 . Diets providing $16: 0$ in the $s n-2$ position resulted in significantly lower TC concentrations that diets providing $16: 0$ in the $s n-1,3$ position $(P=0 \cdot 02)$. Level of dietary $18: 2 n-6$ did not significantly influence fasting TC concentrations. No significant effect of diet was observed on HDL- or LDL-cholesterol or fasting TAG concentrations. C-reactive protein levels observed in subjects during all test diets were less than $1.0 \mathrm{mg} / \mathrm{l}$ (data not shown).

\section{Total cholesterol:high-density lipoprotein-cholesterol ratio}

Consuming diets that contained 16:0 in the $s n-2$ position with low- or high-18:2n-6 resulted in a modest, but statistically significant $(P=0.0001)$, reduction in TC:HDL ratio when 
Table 2. Nutrient content of $s n-1,316: 0$ and sn-2 16:0 dietary treatments* (Percentages of total energy)

\begin{tabular}{|c|c|c|c|c|c|c|c|c|}
\hline \multirow[b]{2}{*}{ Energy source } & \multicolumn{2}{|c|}{ sn-2 $16: 0$ low-18:2n-6 } & \multicolumn{2}{|c|}{$s n-1,316: 0$ low-18:2n-6 } & \multicolumn{2}{|c|}{ sn-2 $16: 0$ high-18: $2 n-6$} & \multicolumn{2}{|c|}{$s n-1,316: 0$ high-18:2n-6 } \\
\hline & $\begin{array}{l}\text { Nutrient } \\
\text { analysis } \\
\text { software }\end{array}$ & $\begin{array}{l}\text { Laboratory } \\
\text { analysis }\end{array}$ & $\begin{array}{l}\text { Nutrient } \\
\text { analysis } \\
\text { software }\end{array}$ & $\begin{array}{l}\text { Laboratory } \\
\text { analysis }\end{array}$ & $\begin{array}{l}\text { Nutrient } \\
\text { analysis } \\
\text { software }\end{array}$ & $\begin{array}{l}\text { Laboratory } \\
\text { analysis }\end{array}$ & $\begin{array}{l}\text { Nutrient } \\
\text { analysis } \\
\text { software }\end{array}$ & $\begin{array}{c}\text { Laboratory } \\
\text { analysis }\end{array}$ \\
\hline Energy (kJ/d) & 12560 & & 12560 & & 12560 & & 12560 & \\
\hline Total fat & 33.1 & 31.5 & $29 \cdot 6$ & $30 \cdot 2$ & $35 \cdot 7$ & $36 \cdot 8$ & $31 \cdot 0$ & $30 \cdot 1$ \\
\hline $16: 0$ & 8.33 & 7.91 & 9.94 & $11 \cdot 0$ & 7.49 & $6 \cdot 69$ & 9.06 & 9.58 \\
\hline $18: 0$ & 4.05 & 4.00 & 1.42 & 1.66 & 3.81 & 4.47 & 1.44 & 1.47 \\
\hline MUFA & $12 \cdot 8$ & $12 \cdot 1$ & $11 \cdot 3$ & $12 \cdot 0$ & 11.5 & $16 \cdot 4$ & 7.73 & $10 \cdot 1$ \\
\hline $18: 2 n-6$ & 3.06 & $3 \cdot 11$ & 3.02 & $2 \cdot 69$ & $8 \cdot 21$ & $6 \cdot 77$ & 8.96 & 8.68 \\
\hline $18: 3 n-3$ & 0.31 & 0.26 & 0.21 & 0.14 & 0.25 & 0.39 & 0.15 & 0.17 \\
\hline Cholesterol (mg/d) & 347 & & 259 & & 332 & & 296 & \\
\hline Dietary fibre $(\mathrm{g} / \mathrm{d})$ & $19 \cdot 2$ & & $25 \cdot 9$ & & $23 \cdot 7$ & & $24 \cdot 1$ & \\
\hline $\mathrm{Ca}(\mathrm{mg} / \mathrm{d})$ & 1000 & & 1140 & & 1050 & & 1020 & \\
\hline Dairy 16:0† & & 0.35 & & 1.80 & & 0.00 & & 1.67 \\
\hline $\begin{array}{l}\text { Lard or palmstearin } \\
\qquad 16: 0 \dagger\end{array}$ & & $7 \cdot 23$ & & $7 \cdot 62$ & & $6 \cdot 55$ & & $6 \cdot 84$ \\
\hline Total sn-2 16:0† & & $5 \cdot 74$ & & 1.98 & & $6 \cdot 39$ & & 1.80 \\
\hline$P: S$ ratio & 0.35 & & 0.30 & & 0.84 & & 0.81 & \\
\hline
\end{tabular}

18: 0 , Stearic acid; $18: 3 n-3, \alpha$-linoleic acid; P:S ratio, polyunsaturated:saturated fat ratio.

${ }^{*}$ All values were derived using Food Processor II nutrient analysis software version 7.71 (ESHA Research, Salem, OR, USA). Some values were obtained from laboratory analysis. Meals were analysed in duplicate.

$\dagger 16: 0$ Values were acquired from direct laboratory analysis (Sheppard et al. 1978).

compared with consuming diets containing 16:0 in the $s n-1,3$ position with low- or high-18:2n-6 (Table 3). Consuming diets with high-18:2n-6 resulted in a statistically lower TC:HDL ratio than consuming low-18 $: 2 n-6$ diets $(P=0 \cdot 003)$.

\section{Cholesterol fractional synthesis rate}

The FSR for total non-esterified cholesterol was significantly lower in subjects consuming the $s n-1,316: 0$ and low$18: 2 n-6$ diet compared with consuming all other diets $(P=0.01)$ (Table 4). The effect of consuming $s n-1,3$ 16:0 compared with $s n-2$ 16:0 on non-esterified cholesterol FSR was not significant.

\section{Discussion}

The findings of the present study indicate that feeding diets with 16:0 in the TAG $s n-2$ position to young, normocholesterolaemic men results in modestly lower fasting serum TC concentrations and a lower fasting TC:HDL ratio than feeding 16:0 in the $s n-1,3$ position (Table 3 ). Further, the present study supports previous observations indicating that the provision of dietary $18: 2 n-6$ at levels of $5 \%$ total energy or greater has a significant cholesterol-lowering effect, especially in the presence of high dietary 16:0 (Hayes \& Khosla, 1992; Sundram et al. 1995; Hayes, 1997; Clandinin et al. 2000; French et al. 2002).

The finding of lower fasting TC concentrations in response to feeding 16:0 in the $s n-2$ position from lard compared with the $s n-1,3$ positions from palmstearin to normocholesterolaemic males is not similar to a previous research study investigating influence of positional distribution of 16:0 from palm oil or lard on blood lipids in human subjects. Zhang et al. (1997) fed Chinese men and women diets high in refined, bleached palm oil, or diets high in lard. The diets were administered for 6 weeks using normal Chinese foods and provided $30 \%$ energy as total fat (Zhang et al. 1997). The diet fatty acid composition was similar to the present study in that $16: 0$ level

Table 3. Plasma lipid and lipoprotein cholesterol concentrations $(\mathrm{mmol} / \mathrm{l})$ in subjects consuming each diet treatment ${ }^{\star}$ (Mean values with their standard errors)

\begin{tabular}{|c|c|c|c|c|c|c|c|c|c|c|}
\hline & \multicolumn{9}{|c|}{ Diet treatment } & \\
\hline & \multicolumn{2}{|c|}{$\begin{array}{c}\text { sn-2 } 16: 0 \text { low- } \\
18: 2 n-6\end{array}$} & \multicolumn{2}{|c|}{$\begin{array}{l}s n-1,316: 0 \\
\text { low-18:2n-6 }\end{array}$} & \multicolumn{2}{|c|}{$\begin{array}{c}\text { sn-2 16:0 } \\
\text { high-18:2n-6 }\end{array}$} & \multicolumn{2}{|c|}{$\begin{array}{r}\text { sn-1, } 316: 0 \\
\text { high-18:2n-6 }\end{array}$} & \multicolumn{2}{|c|}{ Main effects ${ }^{*}$} \\
\hline & Mean & SEM & Mean & SEM & Mean & SEM & Mean & SEM & $s n-2$ v. sn-1, 3 16:0 & Low- $v$. high-18: $2 n-6$ \\
\hline $\mathrm{TC}$ & 4.4 & 0.2 & $4 \cdot 6$ & 0.2 & $4 \cdot 2$ & 0.2 & 4.4 & 0.2 & $P=0.02$ & NS \\
\hline HDL-cholesterol & $1 \cdot 0$ & 0.04 & 1.0 & 0.05 & 1.0 & 0.04 & $1 \cdot 0$ & 0.04 & NS & NS \\
\hline LDL-cholesterol & $2 \cdot 8$ & 0.1 & $2 \cdot 9$ & 0.2 & $2 \cdot 7$ & 0.2 & $2 \cdot 7$ & 0.2 & NS & NS \\
\hline TAG & $1 \cdot 2$ & 0.2 & $1 \cdot 6$ & 0.3 & $1 \cdot 2$ & 0.2 & 1.5 & 0.5 & NS & NS \\
\hline TC:HDL ratio & $4 \cdot 3$ & 0.3 & 4.8 & 0.3 & $4 \cdot 2$ & 0.3 & 4.4 & 0.3 & $P=0.0001$ & $P=0.003$ \\
\hline
\end{tabular}

TC, total cholesterol.

${ }^{*}$ No significant interactions were found. 
Table 4. Total non-esterified cholesterol fractional synthesis rates in subjects consuming each diet treatment

(Mean values with their standard errors)

Fractional synthesis rate (pools/d)

\begin{tabular}{llc}
\cline { 2 - 3 } Diet treatment & Mean & SEM \\
\hline sn-2 16:0 low-18:2n-6 & $0.054^{\mathrm{a}}$ & 0.005 \\
sn-1, 3 16:0 low-18:2n-6 & $0.040^{\mathrm{b}}$ & 0.004 \\
sn-2 16:0 high 18:2n-6 & $0.053^{\mathrm{a}}$ & 0.004 \\
sn-1, 3 16:0 high 18:2n-6 & $0.062^{\mathrm{a}}$ & 0.003 \\
\hline
\end{tabular}

${ }^{\mathrm{a}, \mathrm{b}}$ Mean values with unlike superscript letters are significantly different $(P<0.05)$.

was higher while 18:0 and dietary cholesterol were lower in the diets providing palm oil compared with those providing lard. Lower serum TC and LDL-cholesterol levels, as well as a lower TC:HDL ratio, were found after feeding the diet containing 16:0 in the $s n-1,3$ positions from palm oil. Differences in fasting serum cholesterol levels compared with the present study could be the attributed ethnicity of the subjects, and/or the type of palm oil administered (refined, bleached palm oil $v$. palmstearin).

In the present study, an explanation for higher fasting TC and TC:HDL ratio after the feeding the diets rich in palmstearin could be due to the higher and lower content of 16:0 and 18:0 respectively, compared with the diets rich in lard. Despite all attempts to maintain similar dietary fatty acid composition among diets, the diets providing 16:0 in the $s n-1,3$ from palmstearin had on average 3\% more 16:0 and 2\% less 18:0 than the diets providing $s n-2$ 16:0 from lard (Table 2). Palmitic acid has been shown to be more cholesterolaemic than 18:0 in human dietary interventions (Bonanome \& Grundy, 1988). The highest TC concentration was observed in the $s n-1,3$ 16:0 low-18:2n-6 dietary treatment, which contained the highest level of $16: 0$, at $11 \%$ (Table 2). This observation confirms the plasma cholesterol-raising potential of dietary 16:0.

The present study presented a novel measure of cholesterolaemia through the assessment of $24 \mathrm{~h}$ cholesterol FSR using the ${ }^{2} \mathrm{H}$ incorporation method. Diets providing 16:0 in the $s n-1,3$ positions with a low level of $18: 2 n-6$ resulted in the lowest non-esterified cholesterol FSR compared with all other diets (Table 4). However, despite lower cholesterol FSR, the $s n-1,3$ 16:0 low-18:2n-6 diet did not have a lower TC or TC:HDL ratio (Table 3). Differences in cholesterol FSR and fasting lipoprotein concentrations suggest that measurement of $24 \mathrm{~h}$ cholesterol FSR may not fully explain changes observed in fasting serum TC concentrations. Further, feeding $16: 0$ in the $s n-2$ position at a low intake of $18: 2 n-6$ may not be metabolically equivalent in terms of the effect on cholesterol synthesis compared with feeding 16:0 in the $s n-1$, 3 positions.

Using ${ }^{2} \mathrm{H}$, it has been shown that the rate of cholesterol synthesis is greater in normal and hyperlipidaemic human subjects fed diets high in $18: 2 n-6 v$. those high in saturated fats (Mazier \& Jones, 1991, 1999; Jones et al. 1994a,b, 1998). Plasma TC and LDL-cholesterol concentrations also display an inverse relationship with cholesterol synthesis in response to $18: 2 n-6$ intake. Jones et al. (1994a,b) studied cholesterol synthesis using ${ }^{2} \mathrm{H}$ incorporation in mildly hypercholesterolaemic patients consuming diets containing $30 \%$ total energy as fat from maize, olive, rapeseed, or rice bran oils, or beef tallow. Higher cholesterol FSR was observed for the diet rich in maize oil, which is naturally abundant in $18: 2 n-6$, compared with all other diets. The observations of higher cholesterol FSR with $18: 2 n-6$ consumption have also been seen by Mazier \& Jones (1997). In this study, nine young, normocholesterolaemic men were fed diets containing $40 \%$ total energy from fat rich in either safflower-seed oil (rich in $18: 2 n-6$ ), olive oil or butter for $21 \mathrm{~d}$. Serum TC concentrations were lowest $(P<0.001)$ after consumption of the diet rich in safflower-seed oil, yet cholesterol FSR was highest (Mazier \& Jones, 1997). Clandinin et al. (1999, 2000) demonstrated that diets fed to normocholesterolaemic subjects containing high and low levels of 16:0 from palmolein with high and low levels of $18: 2 n-6$ had no significant effect of endogenous cholesterol synthesis, suggesting no relationship between 16:0 and cholesterolgenesis. However, in these studies, diets that were low in 18:2n-6 had lower FSR for non-esterified cholesterol than those high in $18: 2 n-6$. Further, serum TC concentrations were slightly lower with high $18: 2 n-6$ intake, but these results were not statistically significant. In summary, investigations using ${ }^{2} \mathrm{H}$ incorporation to measure cholesterol FSR suggest that dietary $18: 2 n-6$ increases cholesterol synthesis while decreasing fasting cholesterol concentrations (Mazier \& Jones, 1991). This inverse relationship between circulating cholesterol and cholesterol biosynthesis may be explained by alterations in the hepatic non-esterified cholesterol pool, which is shown to decrease during high 18:2n-6 feeding (Mazier \& Jones, 1999). In response to a smaller hepatic pool of non-esterified cholesterol, LDL-receptors are up regulated and cholesterol synthesis is increased to compensate for the decreased plasma cholesterol concentrations due to increased fractional catabolic rate of LDL (Dietschy et al. 1993).

In summary, in the present study, diets providing 16:0 in the $s n-2$ position from lard may result in slightly lower fasting cholesterol levels than diets providing 16:0 in the sn-1, 3 positions from palmstearin, which is probably a result of a lower total dietary intake of $16: 0$. Further, the endogenous synthesis of cholesterol is significantly affected by the dietary level of $n-6$ polyunsaturated fat.

\section{Acknowledgements}

The authors gratefully appreciate the cooperation of study subjects. The present study was supported by grants from the Natural Sciences and Engineering Research Council of Canada and the Malaysian Palm Oil Board.

\section{References}

Altman P (1961) Blood and Other Body Fluids. Washington, DC: Federation of American Societies of Experimental Biology.

Bell L, Jones PJH, Telch J, Clandinin MT \& Pencharz PB (1985) Predictions of energy needs for clinical-studies. Nutr Res 5, 123-129.

Bonanome A \& Grundy SM (1988) Effect of dietary stearic acid on plasma cholesterol and lipoprotein levels. $N$ Engl J Med 318, 1244-1248. 
Choudhury N, Truswell AS \& McNeil Y (1997) Comparison of plasma lipids and vitamin $\mathrm{E}$ in young and middle-aged subjects on potato crisps fried in palmolein and highly oleic sunflower oil. Ann Nutr Metab 41, 137-148.

Clandinin MT, Cook SL, Konard SD \& French MA (2000) The effect of palmitic acid on lipoprotein cholesterol levels. Int J Food Sci Nutr 51, Suppl., S61-S71.

Clandinin MT, Cook SL, Konard SD, Goh YK \& French MA (1999) The effect of palmitic acid on lipoprotein cholesterol levels and endogenous cholesterol synthesis in hyperlipidemic subjects. Lipids 34, Suppl., S121-S124.

Decker EA (1996) The role of stereospecific saturated fatty acid positions on lipid nutrition. Nutr Rev 54, 108-110.

Dietschy JM, Turley SD \& Spady DK (1993) Role of liver in the maintenance of cholesterol and low density lipoprotein homeostasis in different animal species, including humans. J Lipid Res 34, $1637-1659$.

Emken EA, Adlof RO, Duval SM, Shane JM, Walker PM \& Becker C (2004) Effect of triacylglycerol structure on absorption and metabolism of isotope-labeled palmitic and linoleic acids by humans. Lipids 39, 1-9.

Filer LJ Jr, Mattson FH \& Fomon SJ (1969) Triacylglycerol configuration and fat absorption by the human infant. J Nutr 99, 293-298

Folch J, Lees M \& Sloane Stanley GH (1957) A simple method for the isolation and purification of total lipides from animal tissues. J Biol Chem 226, 497-509.

French MA, Sundram K \& Clandinin MT (2002) Cholesterolaemic effect of palmitic acid in relation to other dietary fatty acids. Asia Pac J Clin Nutr 11, Suppl. 7, S401-S407.

Ghafoorunissa (1995) Nutrition \& health implications of palm oil in Indian diets. Indian J Med Res 102, 233-240.

Gupta SV, Yamada N, Fungwe TV \& Khosla P (2003) Replacing $40 \%$ of dietary animal fat with vegetable oil is associated with lower HDL cholesterol and higher cholesterol ester transfer protein in cynomolgus monkeys fed sufficient linoleic acid. $J$ Nutr 133, 2600-2606.

Hayes KC (1997) The linoleic acid content of test diets must be carefully monitored in cholesterol studies. Am J Clin Nutr 65, $1087-1088$

Hayes KC \& Khosla P (1992) Dietary fatty acid thresholds and cholesterolemia. FASEB J 6, 2600-2607.

Hunter JE (2001) Studies on effects of dietary fatty acids as related to their position on triglycerides. Lipids 36, 655-668.

Idris CA \& Sundram K (2002) Effect of dietary cholesterol, trans and saturated fatty acids on serum lipoproteins in non-human primates. Asia Pac J Clin Nutr 11, Suppl. 7, S408-S415.

Innis SM, Dyer R \& Nelson CM (1994) Evidence that palmitic acid is absorbed as $s n-2$ monoacylglycerol from human milk by breast-fed infants. Lipids 29, 541-545.

Jones PJ (1990) Use of deuterated water for measurement of shortterm cholesterol synthesis in humans. Can J Physiol Pharmacol 68, 955-959.

Jones PJ, Ausman LM, Croll DH, Feng JY, Schaefer EA \& Lichtenstein AH (1998) Validation of deuterium incorporation against sterol balance for measurement of human cholesterol biosynthesis. J Lipid Res 39, 1111-1117.

Jones PJ, Leitch CA, Li ZC \& Connor WE (1993) Human cholesterol synthesis measurement using deuterated water. Theoretical and procedural considerations. Arterioscler Thromb 13, 247-253.

Jones PJ, Lichtenstein AH \& Schaefer EJ (1994a) Interaction of dietary fat saturation and cholesterol level on cholesterol synthesis measured using deuterium incorporation. J Lipid Res 35, $1093-1101$

Jones PJ, Lichtenstein AH, Schaefer EJ \& Namchuk GL (1994b) Effect of dietary fat selection on plasma cholesterol synthesis in older, moderately hypercholesterolemic humans. Arterioscler Thromb 14, 542-548.

Khosla P \& Hayes KC (1993) Dietary palmitic acid raises plasma LDL cholesterol relative to oleic acid only at a high intake of cholesterol. Biochim Biophys Acta 1210, 13-22.

Khosla P \& Sundram K (1997) Effects of dietary palmitic acid and oleic acids on lipoprotein cholesterol. Am J Clin Nutr 65, 170-171.

Kritchevsky D (1988) Effects of triacylglycerol structure on lipid metabolism. Nutr Rev 46, 177-181.

Kritchevsky D, Tepper SA, Czarnecki SK \& Sundram K (2002) Red palm oil in experimental atherosclerosis. Asia Pac J Clin Nutr 11, Suppl. 7, S433-S437.

Kuksis A \& Myher JJ (1989) Gas chromatographic analysis of plasma lipids. Adv Chromatogr 28, 267-332.

Kuksis A, Myher JJ \& Geher K (1993) Quantitation of plasma lipids by gas-liquid chromatography on high temperature polarizable capillary columns. J Lipid Res 34, 1029-1038.

Kuksis A, Myher JJ \& Sandra P (1990) Gas-liquid chromatographic profiling of plasma lipids using high-temperature-polarizable capillary columns. J Chromatogr 500, 427-441.

Lien EL, Boyle FG, Yuhas R, Tomarelli RM \& Quinlan P (1997) The effect of triacylglycerol positional distribution on fatty acid absorption in rats. J Pediatr Gastroenterol Nutr 25, $167-174$.

Mattson FH \& Grundy SM (1985) Comparison of effects of dietary saturated, monounsaturated, and polyunsaturated fatty acids on plasma lipids and lipoproteins in man. J Lipid Res 26, 194-202.

Mazier MJ \& Jones PJ (1991) Dietary fat quality and circulating cholesterol levels in humans: a review of actions and mechanisms. Prog Food Nutr Sci 15, 21-41.

Mazier MJ \& Jones PJ (1997) Diet fat saturation and feeding state modulate rates of cholesterol synthesis in normolipidemic men. J Nutr 127, 332-340.

Mazier MJ \& Jones PJ (1999) Dietary fat saturation, but not feeding state, modulates rates of cholesterol esterification in normolipidemic men. Metabolism 48, 1210-1215.

Meijer GW \& Westrate JA (1997) Interesterification of fats in margarine: effect on blood lipids, blood enzymes, and hemostasis parameters. Eur J Clin Nutr 51, 527-534.

Myher JJ \& Kuksis A (1979) Stereospecific analysis of triglycerols via racemic phosphatidylcholines and phospholipase C. Can J Biochem 57, 117-124.

Nelson CM \& Innis SM (1999) Plasma lipoprotein fatty acids are altered by the positional distribution of fatty acids in infant formula triacylglycerols and human milk. Am J Clin Nutr 70, $62-69$.

Nestel PJ, Pomeroy S, Kay S, Sasahara T \& Yamashita T (1998) Effect of a stearic acid-rich, structured triacylglycerol on plasma lipid concentrations. Am J Clin Nutr 68, 1196-1201.

Ng TK, Hayes KC, DeWitt GF, Jegathesan M, Satgunasingam N, Ong AS \& Tan D (1992) Dietary palmitic acid and oleic acids exert similar effects on serum cholesterol and lipoprotein profiles in normocholesterolemic men and women. J Am Coll Nutr 11, 383-390.

Renaud SC, Ruf JC \& Petithory D (1995) The positional distribution of fatty acids in palm oil and lard influences their biological effects in rats. $J$ Nutr 125, 229-237.

Sheppard AJ, Iverson JL \& Weihrauch JL (1978) Composition of selected dietary fats, oils, margarines, and butter. In Fatty Acids and Glycerides, pp. 341-375 [A Kuksis, editor]. New York: Plenum Press.

Sundram K, Hayes KC \& Siru OH (1995) Both dietary 18:2 and 16:0 may be required to improve the serum LDL/HDL cholesterol ratio in normocholesterolemic Men. J Nutr Biochem 6, 179-187. 
Truswell AS (2000) Comparing palmolein with different predominantly monounsaturated oils: effect on plasma lipids. Int J Food Sci Nutr 51, Suppl., S73-S77.

Yli-Jokipii KM, Schwab US, Tahvonen RL, Kurvinen JP, Mykkanen HM \& Kallio HP (2002) Triacylglycerol molecular weight and to a lesser extent, fatty acid positional distribution, affect chylomicron triacylglycerol composition in women. $J$ Nutr 132, 924-929.
Zhang J, Ping W, Chunrong W, Shou CX \& Keyou G (1997) Nonhypercholesterolemic effects of a palm oil diet in Chinese adults. $J$ Nutr 127, 509S-513S.

Zock PL, de Vries JH, de Fouw NJ \& Katan MB (1995) Positional distribution of fatty acids in dietary triacylglycerols: effects on fasting blood lipoprotein concentrations in humans. Am J Clin Nutr 61, 48-55. 